\title{
ACERCAMIENTOS AL TEATRO CENTROAMERICANO CONTEMPORÁNEO
}

\section{APPROACHES TO CONTEMPORARY CENTRAL AMERICAN THEATER}

\author{
Revista Trama \\ Volumen 10, número 1 \\ Enero - Junio 2021 \\ Páginas 166-178 \\ ISSN: 1659-343X \\ https://revistas.tec.ac.cr/trama
}

Adriano Corrales Arias $\mathbf{1 , 2}$

Fecha de recepción: 3 de junio, 2020.

Fecha de aprobación: 28 de junio, 2021.

Corrales, A. (2021). Acercamientos al teatro centroamericano contemporáneo. Trama, Revista de ciencias sociales y humanidades, Volumen 10, (1), Enero-Junio, págs. 166-178

DOI: https://doi.org/10.18845/tramarcsh.v10i1.5788

1. Profesor, Escuela de Cultura y Deporte, Campus local de San José, Instituto Tecnológico de Costa Rica. San José, Costa Rica. 


\section{RESUMEN}

Lo que sigue es un ensayo de interpretación sobre la actualidad de la actividad teatral en Centroamérica. El mismo se propone como insumo o acercamiento para un debate, que debería conducir a ciertos niveles de diálogo y de posibles abordajes más o menos prácticos sobre la problemática planteada, así como a la posibilidad de mapear y "reconstruir" lo que ocurre en la irregular escena de la región.

Palabras clave: Teatro, artes escénicas, dramaturgia, Centroamérica.

\section{ABSTRACT}

What follows is an interpretive essay on the actuality of theater activity in Central America. It is proposed as an input or approach for a debate, which should lead to certain levels of dialogue and possible more or less practical approaches to the problem raised, as well as the possibility of mapping and "reconstructing" what happens in the irregular scene of the region.

Key words: Theater, performing arts, dramaturgy, staging, Central America. 


\section{BREVE INTRODUCCIÓN}

Hablar o escribir sobre "teatro" en Centroamérica es una tarea compleja y difícil. El tema es, además de apasionante, espacioso y general, por tanto hondamente arduo, dadas las particularidades y condiciones de su amplia y profunda propuesta y de sus múltiples expresiones y posibilidades. Se podría abordar, por ejemplo, cuestionando el significado del mismo término "teatro"y del constructo sociohistórico "Centroamérica". Tanto en la academia como en los instituyentes culturales, en las incipientes industrias culturales o desde las culturas populares, ambos conceptos o cuestiones no poseen consensos necesarios.

Para muchos críticos e intelectuales el teatro forma parte de la literatura, para otros, afortunadamente, es un hecho puramente escénico con sus propias especificidades y su particular dramaturgia. El asunto es más grave si hablamos de las artes escénicas en general, pues se tiende a dejar por fuera expresiones como la danza o la ópera. El arte escénico contemporáneo debería contemplar las tres disciplinas en una construcción trans e interdisciplinaria. Por otra parte, para muchos habitantes de este istmo, Centroamérica es una quimera en etapa de construcción, sino que lo digan los panameños o, más recientemente, los beliceños. Igual podríamos mencionar a algunas etnias y grupos sociales que sobreviven en la periferia de los estados-nación, caso de los Garífunas, para mencionar un pueblo multinacional centroamericano.

Por cierto, ¿qué sabemos de la escena en Belice o en Panamá? Es probable que para muchos de nosotros se torne difícil hablar de la escena teatral en nuestros propios países, dada la casi imposibilidad de abordar las diferentes expresiones escénicas y parateatrales de nuestras pequeñas y asimétricas naciones. Para hablar de artes escénicas se precisa de una visión de conjunto y, para hablar de actividad teatral en determinado lugar, es preciso participar de esta, ya como agentes, ya como espectadores. $Y$ bien sabemos lo difícil que es hacer y mirar teatro en Centroamérica, para no mencionar la danza y la ópera en sus variadas formas y yuxtaposiciones. Una de las pocas posibilidades que tenemos son los festivales centroamericanos, escasos de cualquier modo. Pero es difícil tomarle el pulso al quehacer escénico de alguno de nuestros países a partir de un espectáculo aislado o del conocimiento de un grupo o de una compañía concretos. Sabemos que no todos los grupos o compañías participan en los festivales por razones de producción y/o de posibilidades económicas y financieras, las cuales son el permanente conflicto de las artes escénicas en nuestras tierras. Por lo demás, es agotador apreciar todos los espectáculos de un mismo festival. 
Por otra parte, las carencias propias del teatro centroamericano tornan difícil la profesionalización de la actividad. Guatemala y Costa Rica son los países con más avances en ese sentido, así como en la formación académica o en la certificación de pregrados en artes escénicas. Ante ese precario panorama, es urgente la capacitación y formación sostenida de los artistas escénicos. A ello debemos agregar el hecho de no contar con públicos amplios y motivados, salvo contadas excepciones; tampoco con una prensa y una crítica plural y avisada que evalúe y de cuenta de los eventos para que personas que no pueden asistir tengan una perspectiva de lo acontecido, o para que estudiosos e investigadores puedan tener acceso a documentos e insumos susceptibles de ser procesados y ordenados desde la reflexión crítica y/o historiográfica. La mayor de las veces son los mismos teatristas quienes realizan las crónicas y las críticas para que sus trabajos no se pierdan en el farragoso transcurrir de nuestros tiempos; de allí la ausencia de verdaderos sistemas de datos y de archivos escénicos. Si a ello añadimos la emergencia de las artes visuales, especialmente del cine, tendremos un panorama poco halagüeño.

De tal manera que no pretendo realizar diagnóstico alguno ni tampoco un recuento del estado de la cuestión o de sus principales contenidos. Por lo mencionado y por el espacio de esta comunicación, la puntulización sobrepasa mis posibilidades e intenciones. A cambio propongo una serie de reflexiones, como insumos o acercamientos para un debate, que debería conducirnos a ciertos niveles de diálogo y de posibles abordajes más o menos prácticos sobre la problemática planteada, como una posibilidad de mapear y de "reconstruir" lo que ocurre en la irregular escena de la región. 


\section{LA CRISIS DEL TEATRO OCCIDENTAL}

Lo primero que debe subrayarse es que el teatro occidental, o mejor aún, la formación discursiva teatral de occidente, está en crisis. Su propia esencia artística no puede competir con el mercado, pues no se puede masificar; esa contradicción, bien vista, es una ventaja comparativa, pero también una limitación y una amenaza. Por demás, la actividad teatral, como dispositivo institucional, se ha desconectado de la realidad inmediata, de su cotidianidad. Dicho de otro modo, se ha distanciado del cuerpo social y de sus conflictos, de la corporalidad ciudadana atravesada por la economía de mercado global y su "colonialidad del poder" ${ }^{3}$. A ello debemos agregar la caída del Estado Social de Derecho, o del Estado Benefactor $y$, por ende, de la subvención estatal a la actividad artística, específicamente escénica. En Europa son decenas los teatros que han debido cerrar por esa crisis. En Centroamérica, es Costa Rica quizás el país que atraviesa por una situación similar, dado el cambio de paradigma o la transición de un estado benefactor a un estado neoliberal que constriñe su labor encomendándole las tareas culturales a la empresa privada, es decir, a las incipientes industrias culturales.

\footnotetext{
3. Según Aníbal Quijano (2000), colonialidad del poder es un concepto que da cuenta de uno de los elementos fundacionales del actual sistema de poder global: la clasificación social básica y universal de la población del planeta en torno a la idea de "raza"; las "razas superiores" ocupan los mejores puestos en la cadena productiva, las inferiores los marginales. Esta noción y la clasificación social que comporta se originan, junto con los conceptos de América, Europa y el capitalismo, hace 500 años. Son la más profunda y perdurable expresión de la dominación colonial impuesta en el curso de la expansión del colonialismo europeo. Desde entonces, en el actual patrón mundial de poder, impregnan todas y cada una de las áreas de la vida social y constituyen la más profunda y eficaz forma de dominación sociocultural, material e intersubjetiva, y son, por eso mismo, la base universal de dominación política dentro en el actual sistema-mundo. Es útil subrayar que los términos "colonialidad" y"colonialismo" dan cuenta de fenómenos y de cuestiones diferentes. El "colonialismo" no se refiere a la clasificación social universalmente básica que existe en el mundo desde hace 500 años, sino a la dominación político-económica de unos pueblos sobre otros y es miles de años anterior a la colonialidad. Ambos términos están relacionados: la colonialidad del poder no habría sido posible, por supuesto, sin el específico colonialismo europeo. Es decir, la colonialidad del poder tiene origen y carácter colonial y es el rostro oculto de la modernidad capitalista, pero ha probado ser más duradera y estable que el colonialismo, en cuya matriz fue establecida. Implica un elemento en el patrón de poder hoy mundialmente hegemónico. Se trata de una perspectiva del mundo, la especie y la historia que, elaborada sistemáticamente en Europa desde el siglo XVII, logró ser impuesta en el "centro" y "las periferias", como racionalidad única, y logró hegemonía en el mundo como resultado de la misma colonialidad del poder.
} 
De tal suerte que, mientras nos preguntamos por los movimientos teatrales centroamericanos, debemos cuestionar los movimientos teatrales al interior de cada país. Un verdadero movimiento teatral no se nutre únicamente de la producción dramatúrgica; el escritor que se aboca a la dramaturgia necesita ver sus obras representadas, y para ver sus obras representadas precisa de un público que justifique la puesta en escena. En otras palabras, un movimiento teatral sólido requiere de productores dramatúrgicos, productores de escena (actores, directores, compositores, músicos, escenógrafos, diseñadores, et.al.) y de públicos que hagan posible la puesta en escena; pero, además, de una crítica profesional que oriente a ese público en términos de la recepción del producto escénico, con publicaciones periódicas y especializadas que alimenten el diálogo y la discusión.

Para todo lo anterior, se precisa de formación teórica y técnica, es decir, de una estructura que garantice la formación, tanto de teatristas como de críticos teatrales $y$, por extensión, de públicos cada vez más amplios e informados. Dicha estructura puede ser académica, en el sentido tradicional, o procedente de esfuerzos de la sociedad civil o de grupos independientes o comunitarios, que son los más dados a suplir esa labor dado el escaso apoyo de los estados centroamericanos a la actividad, especialmente en la actual coyuntura signada por el modelo neoliberal globalizado y transnacional.

Lo planteado coloca, en el centro del debate, la posibilidad de realizar "teatro de arte" o "teatro comercial", como se les conoce peyorativamente 4 . Sin profundizar en la pertinencia de esa dicotomía, la cual se entiende como un campo de batalla en el escabroso campo cultural, no hay duda de que sus supuestos y coordenadas ameritan un análisis profundo, en función de las dinámicas y características propias del campo artístico-cultural en el ámbito centroamericano, con sus

\footnotetext{
4. La disyuntiva es un tanto hiperbólica y maniquea. Para efectos de esta comunicación, entenderemos el "teatro de arte" como un teatro de autor, sea "clásico" o contemporáneo", que antepone la calidad estético-ética a su condición mercantilista; y el "teatro comercial" como aquel destinado, básicamente, al entretenimiento liviano y a la colocación en el mercado artístico cual mercancía que posibilite su autogestión. En esa perspectiva, lo ideal sería una conjunción de ambos, es decir, que el "teatro de arte" pudiese comercializarse y que el "teatro comercial" tuviese calidades artísticas pertinentes; para ello, se precisa de un público avisado y compenetrado con ese tipo de teatro. Son las clases medias y las burguesías ilustradas las que pueden proveer ese público; sin embargo, con la crisis total del capitalismo y sus efectos en países periféricos como los nuestros, esas clases medias son cada vez más escuálidas y la burguesía (los "nuevos ricos" no tan ilustrados) prefiere otro tipo de espectáculos más "intensos", además, puede viajar a Miami o a Las Vegas a disfrutar del "Cirque du soleil", por ejemplo.
} 
especificidades, y en el sistema mundo-global contemporáneo. La escasa ayuda estatal y el exiguo (y sesgado) patrocinio privado o de la cooperación internacional, lanzan a los teatristas hacia el mercadeo de sus propuestas y, por tanto, a la gratuidad de públicos poco exigentes. 


\section{III. ¿QUÉ SUCEDE EN Y CON EL TEATRO CENTROAMERICANO? \\ El acontecer teatral centroamericano de las últimas décadas,} según algunos investigadores, estudiosos (cfr. Cea, Mackenbach, Bell, Bonilla et al.) y los mismos teatristas, ha experimentado un acelerado proceso de comercialización, que ha cedido espacio a producciones y productos de poco valor estético y ético. Esto no solo provoca teatro mal armado y de mal gusto sino que, además, da al traste con las producciones públicas y cívicas de otras posibles propuestas escénicas; es decir, con la construcción de públicos y el desarrollo de dramaturgias propias. Por otra parte sabemos que, paralela y afortunadamente, se ha escrito y producido un teatro diferente, de resistencia cultural y estética, principalmente desarrollado por grupos independientes, alternativos y universitarios. Se ha presentado así, una suerte de "renacimiento" de una dramaturgia y de un teatro de cierta calidad, que incorpora temas de conciencia social y de solidaridad entre los sectores subalternos en busca de sus propias problemáticas e identidades.

Lo anterior está asociado a un fenómeno que algunos críticos denominan "islas" (Visión de ASTAC en Cea: 2000), apuntando al hecho del aislamiento de los mismos grupos y productores teatrales al interior de sus países, a su escasa interacción e intercambio; es decir, a su desarticulación. Esa suerte de atomización teatral que observamos en nuestras ciudades (específicamente en las capitales donde se concentra el mayor dispositivo artístico/cultural) obedece a variadas causas, pero, fundamentalmente, a la "competencia" descarnada por públicos, asentada, generalmente, por celos propios de egos creadores y de cierto individualismo capitalista. A ello debemos sumar, ya lo señalamos, la escasa o nula subvención estatal, lo que obliga a la consecución de recursos por otras fuentes, además de las boleterías. En ese sentido, es deseable que se planteen formas de cooperación y de intercambio entre diversos grupos y compañías; que se tienda hacia la conformación de auténticos movimientos teatrales integrados en cada ciudad y país.

Una política de integración entre diversas agrupaciones teatrales potenciaría la distribución de recursos financieros provenientes de subvenciones o de ayudas de la cooperación internacional; la elaboración de repertorios y carteleras programadas; la programación de actividades de formación técnica y artística, la investigación y la extensión, el intercambio de actores, personal técnico y recursos escenográficos, etc. El intercambio de técnicas y de recursos humanos solo podría redundar en beneficios para la actividad teatral de cada país. Se debe considerar, también, la gestación de una red centroamericana (como las experiencias del proyecto El Carromato o del proyecto Lagartija, para la formación técnica), más allá de los festivales, la cual permita girar grupos 
y compañías de manera concertada por la región, incluidas la danza, la ópera y las expresiones circenses. Así estaríamos avizorando un posible y auténtico movimiento escénico centroamericano.

Al interior de la discusión sobre la integración de los productores y agentes teatrales, se halla otra de índole conceptual y política, por tanto, ética (que, a su vez, es una prolongación de la eterna "teatro de arte" versus "teatro comercial"), pero no por ello menos importante. Se trata del cuestionamiento de la institución arte y sus funciones, así como del mercado artístico, lo que nos remite a la concepción de la producción artística como herramienta para el cambio social. La crítica del individualismo, como eje del proceso creativo y del artista como creador aislado, ha conseguido que muchos artistas occidentales renuncien al estatus del elitismo cultural, para vincularse a problemáticas del contexto social en que se desenvuelven. De allí el surgimiento de lo que se conoce como arte comunitario. Pienso que la escena centroamericana, por su historia, sus características y sus dificultades, debería tomarse muy en serio la construcción de comunidades teatrales y la implementación del teatro comunitario, como propuesta de ampliación de su actividad. 


\section{A MODO DE PROPUESTA}

Pero no se trata de que los teatristas lleven suarte a las comunidades, ello es importante, sin duda; se trata de que las comunidades dejen de ser audiencias posibles y se conviertan en productoras teatrales. Dicho de otro modo, se trata de entregar las armas de la producción escénica a las comunidades tal y como lo han intentado hacer Rafael Murillo Selva-Rendón o Jack Wagner del grupo La Fragua en Honduras, para no ir muy lejos. En esa perspectiva, se trata de que el "artista profesional" se convierta en un facilitador y en un intermediario para coadyuvar a la creación de nuevos agentes teatrales en las comunidades desprovistas de infraestructura y servicios culturales. Ello sin dejar de lado la calidad artística de propuestas y proyectos, ofreciendo, más bien, la posibilidad de descolonizar los lenguajes artísticos para permitir el cambio sociocultural desde la actividad escénica. Es decir, un cambio en los términos de la conversación sociocultural y dramatúrgica, una suerte de liberación comunal a partir del trabajo artístico mancomunado. El arte teatral, por sus características de producción, es una actividad de creación colectiva, por tanto, de acción comunal.

El teatro comunitario no solamente potencia la creatividad histriónica y performativa de los sectores populares, sino que coadyuva a su empoderamiento y a la visibilización de sus identidades (somos países multilingües y pluriculturales), a la vez que sirve de cantera para seleccionar artistas de agrupaciones ya establecidas o las que pudiesen surgir de su propia actividad; asimismo, permite la emergencia de nuevas dramaturgias y nuevos públicos con una formación básica para comprender los entresijos del hecho teatral. Igualmente, alimenta la posibilidad de establecer vínculos de cooperación entre diversas agrupaciones y creadores, quienes deben descolonizar sus prácticas y sus mentes con una visión más amplia. La actividad teatral puede y debe conseguir esas asociaciones y producciones mancomunadas; educar a sus propios agentes para ayudar a despojarse de los individualismos, la "competitividad" y la vanidad, dentro y fuera de las tablas.

Por supuesto, conocemos las dificultades extremas a las que se enfrenta el productor teatral en nuestros países, especialmente en cuanto a la promoción en comunidades; su actividad, casi siempre, está marcada por la estrechez y el desamparo. Ciertamente, las prácticas colaborativas y de promoción teatral en la base suponen diferencias y conflictos, como es propio de la naturaleza del espacio público, pero podrían lograrse proyectos consensuados en los que no existan relaciones problemáticas. La actividad colectiva y consensuada posibilita la superación de conflictos y la construcción de alternativas a la precariedad. Por cierto, las universidades públicas 
centroamericanas tienen mucho que decir y hacer al respecto, aunque también conocemos la grave crisis por la que atraviesan.

Lo cierto es que la actividad teatral es una forma de registrar y exponer lo que el cuerpo social habita y lo que en el cuerpo individual se inscribe: la experiencia corporal es un vehículo privilegiado de comunicación y de síntesis entre el sujeto y su entorno. En el caso centroamericano, se trata de cuerpos atravesados por la herida colonial; por la resistencia y por la muerte; por el amor, el deseo y la violencia psíquico-simbólica. En otras palabras, se trata de experiencias colectivas e individuales complejas y conflictivas aproximables, las más de las veces, solamente a través de la mediación artística mediante la puesta en escena, frente a la cual la construcción dramática apuesta por el cuerpo (individual y social), mientras ocupa un espacio sociocultural (escénico) en un tiempo determinado.

La violencia social, política, económica y simbólica, arraigada en países asimétricos y estructuralmente falseados con profundas diferencias sociales, constituye un elemento central de la historia centroamericana; es una constante como manifestación estética en la historia artístico-literaria del istmo. Durante los años setenta y ochenta del siglo pasado, la representación de la violencia en la escena social centroamericana fue persistente, tanto por parte de quienes dominan y gobiernan contra el resto de la población, como de los oprimidos contra quienes se ejerce el poder. Tal vez esto haya cambiado en la actual escena teatral centroamericana, no así en la escena social; es decir, en las condiciones de nuestros pueblos y sus principales agentes productivos, políticos y socioculturales. Por esas razones debemos realizar esfuerzos para derivar hacia un teatro más vivo con presencia de las comunidades históricamente olvidadas por el Estado y por el arte de élite eurocéntrico. Esa es una de las pocas vías que vislumbro para la sobrevivencia de la magia renovada y concertada de un nuevo teatro regional, más allá del marco de los estados-nación y de la colonialidad del poder. No es la única, pero sí un camino, otro al cual deberíamos prestar mayor atención. 


\section{BIBLIOGRAFÍA}

Bell, C. (2000). El teatro costarricense en transición. En: Carolyn Bell y Patricia Fumero. Drama contemporáneo costarricense: 1980-2000. San José: Universidad de Costa Rica.

Bonilla, M. (2000). Costa Rica y el derecho a soñar: Audacia teatral del siglo XX. Latin American Theatre Review, 34 (1), 79-85.

Cea, J. R. (2000). Para presentar unas visiones: El teatro salvadoreño. Latin American Theatre Review, 34 (1), 103-111.

Mackenbach, W. (2007). Presentación del libro Emergencias: dramaturgia costarricense contemporánea emergente. Leído el 5 de junio de 2007, en el Centro Cultural de España en Costa Rica. Disponible en: www.teatroemergencias.com

Quijano, A. (2000). Colonialidad del Poder, Eurocentrismo y América Latina. En: Edgardo Lander, comp. Colonialidad del Saber, Eurocentrismo y Ciencias Sociales. Buenos Aires: CLACSO-UNESCO. 